\title{
György von Békésy
}

\author{
Ottó Ribári \\ HNO-Klinik der Semmelweis-Universität, Budapest, Ungarn
}

György Békésy wurde am 3. Juni 1899 in Budapest geboren. Sein Vater war Diplomat der österreichischungarischen Monarchie. G. Békésy verbrachte deswegen seine Kindheit in mehreren Ländern, unter anderem in Deutschland (München) und in der Türkei (Istanbul). Die Grundschule absolvierte er in München, das Untergymnasium in Istanbul. Das Gymnasium besuchte er in der Schweiz, nämlich in Zürich und Bern. Das Abitur legte er 1917 in Bern ab. Schon als Schüler sprach er ausser ungarisch auch fliessend deutsch, französisch und italienisch. Zwischen 1918 und 1921 studierte er in Bern Naturwissenschaften, unter anderem Chemie. Zurück in Ungarn studierte er Physik in Budapest und promovierte in diesem Fach im Jahre 1923. Als Promotionsarbeit wählte er ein Thema aus der Optik. Sein erster Arbeitsplatz war das damals renommierte und technisch gut ausgestattete Forschungsinstitut für Kommunikation der ungarischen Post, an welchem er an der Qualitätsverbesserung des Telephonkabels arbeitete. Im Laufe dieser Arbeiten in der Telephontechnik begann er sich für die Funktionsweise des Ohres zu interessieren. In der Folge führte er eine Reihe von wissenschaftlichen Studien durch, die rasch weites Aufsehen erregten. Infolge dieser Arbeiten wurde er 1926 nach Berlin an das Forschungslabor von Siemens eingeladen. 1927 kam er nach Budapest zurück und beschäftigte sich mit technischen Verbesserungen von Mikrophon und Kopfhörer. Aus dieser Zeit stammt ein erstes von Békésy konzipiertes elektrisches Audiometer. Verschiedene Arbeiten befassten sich mit der Schallübertragung im Ohr. Diese Untersuchungen führte er an eigenen anatomischen Ohrpräparaten am Anatomischen Institut der Universität Budapest durch. Die vorherige technische Grundausbildung war ihm für diese mikroskopischen Präparationen von grossem Nutzen.

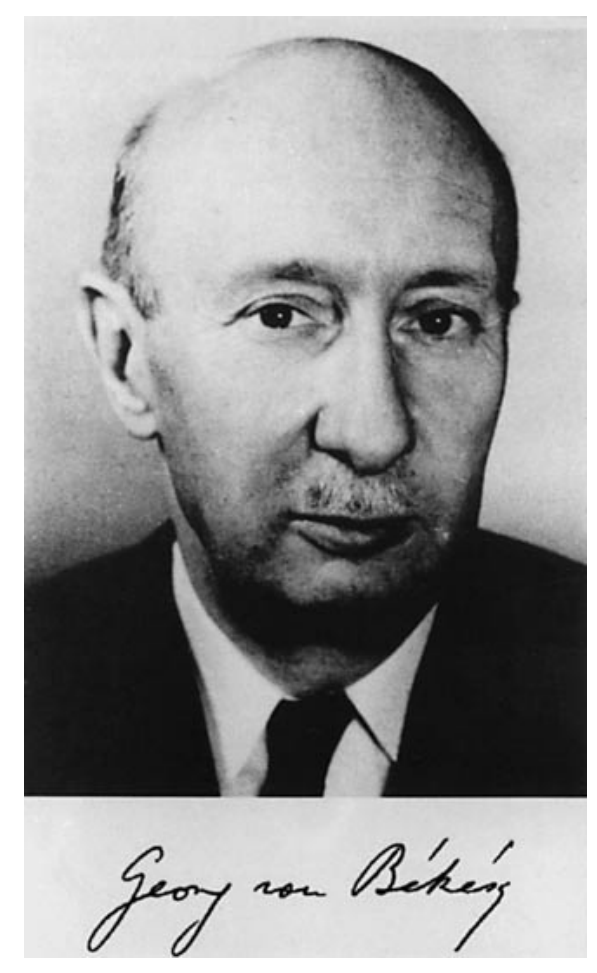

Im Jahre 1928 publizierte er in der «Physikalischen Zeitschrift» eine Arbeit über die Funktionsweise des Innenohrs. Dadurch wurde er in der ganzen Welt bei Physikern, Ingenieuren und Ärzten bekannt. Die Deutsche Otologische Gesellschaft honorierte 1931 Békésys Arbeiten mit dem Denker-Preis. Die Firma Philips lud ihn 1934 für $1 \mathrm{Jahr}$ nach Holland ein. Ab 1935 nahm er wieder Wohnsitz in Budapest, hielt aber zahlreiche Gastvorträge 


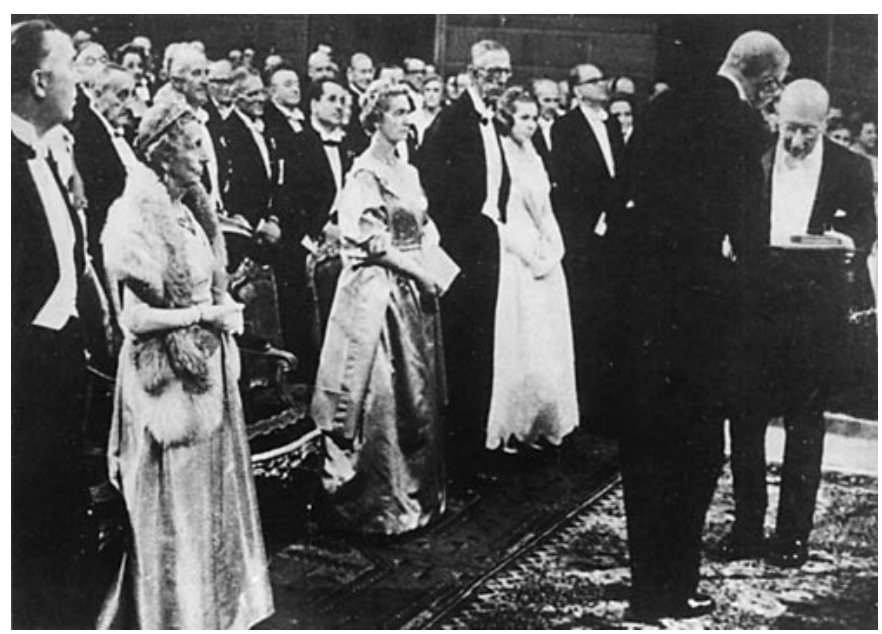

in ganz Europa. Die Preussische Akademie der Wissenschaften zeichnete ihn 1937 für seine Forschungen mit dem Leibniz-Preis aus. 1939 erhielt er den Guyot-Preis der Universität Groningen. Im selben Jahr wurde er in die Ungarische Akademie der Wissenschaften aufgenommen. Seit 1932 Privatdozent, erhielt er 1940 den Lehrstuhl für praktische Physik an der Universität Budapest.

Die Experimente und Entdeckungen von György Békésy haben unser Wissen über die Physik und Physiologie von Mittel- und Innenohr grundsätzlich verändert. Er hat als Physiker neue Aspekte des Hörens entdeckt und allgemein das Interesse an der Hörforschung geweckt. Er analysierte die Schallübertragung im Mittelohr und konzeptuell die mechanisch-elektrische Transduktion im Innenohr. Er hat die Wanderwelle der Basilarmembran im Innenohr direkt am anatomischen Präparat beobachtet. Dies führte schliesslich zu seiner berühmten Wanderwellentheorie der Basilarmembran. 1946 propagierte er das nach ihm benannte automatische Audiometer. Dieses Audiometer liefert wichtige Informationen über die Funktion des Ohrs und wurde später in Stockholm weiter entwickelt. Vielerorts ist es noch heute in Gebrauch.

Das Laboratorium von Békésy war in Budapest 1945 durch den Krieg zerstört worden. Deshalb folgte er 1946 einem Ruf an das Karolinska-Institut nach Stockholm und 1947 an das psychoakustische Forschungslabor der Harvard-Universität in Boston. 1950 erhielt er für seine Forschungsarbeiten den Shambaugh-Preis in den USA und 1955 die Howard-Crosby-Warren-Medal. Im selben Jahr wurde er auch Mitglied der Amerikanischen Akademie der Wissenschaften. Er wurde 1957 von der Amerikanischen Otologischen Gesellschaft ausgezeichnet und 1961 von der Amerikanischen Akustischen Gesellschaft. 1959 wurde er Ehrendoktor der Universität Bern.

Am 10. Dezember 1961 erhielt er als höchste Ehrung den Nobelpreis auf dem Gebiet der medizinischen Physiologie. Als Nobelpreisträger wurde er auf einen Schlag weltbekannt. Er wurde sukzessive zum Ehrendoktor der Universität Padova (1952), des Kollegiums Gustav Adolf in Schweden (1963) und der Universitäten Córdoba (1963), Pennsylvania (1965), Buenos Aires (1968), Budapest (1969) und Hawaii ernannt. 1966 richtete er ein neues Forschungslaboratorium an der Universität Hawaii in Honolulu ein. An diesem Institut für sensorische Wissenschaften verfeinerte er seine Theorien weiter. Speziell interessierte ihn nun das Phänomen der akustischen Verzerrung. Er studierte verschiedene Aspekte des Lärm- und Knalltraumas, und er führte elektrophysiologische Messungen von kochleären Potenzialen durch.

György Békésy starb am 13. Juni 1972 in Honolulu. Seine Bibliothek und seinen wissenschaftlichen Nachlass vermachte er der Universität Honolulu, seine berühmte Kunstsammlung dagegen dem Nobelpreiskomitee in Stockholm.

Békésy hat auf den Gebieten der Telekommunikation, der Akustik und der Gehörphysiologie viel Neues entdeckt und erschaffen. Wir verdanken ihm viele Erkenntnisse auf den Gebieten der Raumakustik, der Telephontechnik und der Nachrichtenübermittlung. Seine Forschungsergebnisse über die Schallleitung im Mittelohr und die Funktionsweise des Innenohres bilden eine wichtige Grundlage für gehörverbessernde Operationen. Speziell zu bemerken ist, dass er schon vor 30 Jahren auf die Möglichkeit der Kochlea-Implantation hingewiesen hat.

G. von Békésys Erkenntnisse erschienen zusammengefasst in «Experiments in Hearing», New York 1960, und «Sensory Inhibition», Princeton 1967. 